\title{
Arbitragem nas Sociedades Limitadas
}

\author{
Arbitration in Limited Liability Companies
}

\author{
ANA CLAUdia REDECKER ${ }^{a}$
}

\begin{abstract}
RESUMO
O presente artigo versa sobre a arbitragem nas sociedades limitadas e aborda, de forma sucinta, as suas características e as razões pelas quais este mecanismo permite soluções rápidas para os conflitos internos da Sociedade que se refiram aos seus sócios, sem o risco de afetar as suas atividades e com isto prejudicar a sua atuação no mercado.

Palavras-chave: Arbitragem. Sociedade limitada. Conflitos.
\end{abstract}

\begin{abstract}
This article focuses on arbitration in limited liability companies and discusses, succinctly, their characteristics and the reasons why this mechanism allows quick solutions to the Company internal conflicts Society regarding their partners without the risk of affecting their activities and thus impair its performance in the market.
\end{abstract}

Keywords: Arbitration. Limited liability companies. Conflicts.

\section{INTRODUÇÃO}

O presente artigo trata da arbitragem nas sociedades limitadas, forma alternativa de solução de litígios ou controvérsias, sem a tutela do poder judiciário. Optouse por abordar a arbitragem na sociedade limitada por se tratar do tipo societário mais utilizado no Brasil, representando mais do que $98 \%$ (noventa e oito por cento) dos contratos que são levados a arquivamento nas Juntas Comerciais.

Partimos de um panorama geral acerca da arbitragem, abordando de forma sucinta o seu surgimento no nosso ordenamento jurídico, conceito e características.

Posteriormente tratamos da arbitragem nas sociedades limitadas buscando responder a alguns questionamentos, tais como: uma vez incluída a cláusula compromissória no contrato social esta será mandatória para todos os sócios? E nas hipóteses em que os sócios não concordem com a adoção da arbitragem ou não tenham comparecido na Reunião de Sócios? Qual a extensão da cláusula compromissória? A interpretação da cláusula compromissória deve ser ampla ou restritiva?

Abordaremos as questões controversas sobre o tema a partir da análise da jurisprudência pátria com o objetivo de deixar o leitor atualizado com o entendimento que tem sido adotado pelos Tribunais.

Por fim, abordaremos as vantagens da adoção da arbitragem nas sociedades limitadas.

\section{AARBITRAGEM NO SISTEMA JURÍDICO BRASILEIRO}

\subsection{Breve histórico}

O primeiro disciplinamento sobre arbitragem foi registrado em 1603, nas Ordenações Filipinas. A decisão arbitral daquela época não estava sujeita à homologação judicial. As Ordenações continuaram em vigor até a promulgação da Constituição de 1824, que

\footnotetext{
a Professora de Direito Empresarial da Pontifícia Universidade Católica do Rio Grande do Sul (PUCRS) e da Escola Superior de Magistratura (Ajuris), Especialista em Ciências Políticas, Mestre em Direito e doutoranda em Ciências Jurídico-Económicas pela Faculdade de Direito da Universidade de Lisboa. Advogada responsável pela área societária da Pandolfo Advogados Associados.
} 
estipulou no artigo 160, in verbis: "Nas civeis e nas penais civilmente intentadas poderão as partes nomear juizes árbitros. Suas sentenças serão executadas sem recurso, se assim o convencionarem as mesmas partes".

O Código Comercial de 1850, nos arts. 139 e 294, determinava que as questões de fato sobre a existência de fraude, dolo, simulação ou omissão culpável na formação dos contratos ou na sua execução, bem como nas questões sociais entre sócios, deveriam ser decididas em juízo arbitral ${ }^{1}$.

O Código Civil de 1916 tratou da arbitragem, sob o título de "compromisso" (arts. 1037 a 1048). No entanto, este instituto não foi utilizado em larga escala como meio de solução de conflitos, pois o Código de Processo Civil (arts. 1085 a 1102), exigia a homologação do então chamado "laudo arbitral", por sentença judicial com todos os recursos inerentes ${ }^{2}$.

A Lei 9.307 de 1996 revogou todos os artigos que tratavam da arbitragem, aboliu a necessidade de homologação judicial da sentença arbitral e equiparou o árbitro ao juiz togado no desempenho da arbitragem, ou seja, inseriu no nosso ordenamento jurídico novo modelo arbitral. No modelo arbitral introduzido pela Lei 9.307/96 foi dada ênfase à autonomia da vontade das partes, as quais podem optar por submeter a resolução de seus conflitos à jurisdição arbitral em substituição à estatal ${ }^{3}$.

\subsection{Conceito e características da arbitragem sob a ótica da Lei $9.307 / 96$}

Arbitragem é um processo alternativo, extrajudicial e voluntário que se utiliza com o objetivo de dar solução a litígio ou controvérsia, havida entre duas ou mais pessoas físicas e jurídicas capazes de contratar, no âmbito dos direitos patrimoniais disponíveis ${ }^{4}$, sem a tutela do poder judiciário.

A escolha pela arbitragem representa liberdade individual por isso não viola a Constituição Federal disposta no artigo 5, XXXV: "A Lei não excluirá do Poder Judiciário lesão ou ameaça a direito". Nesse sentido:

Arbitragem. Ações cautelar e principal que buscam respectivamente, a suspensão do procedimento arbitral e sua nulidade. Impossibilidade de manifestação pelo Poder Judiciário. Arbitragem que é exceção ao princípio do livre acesso à justiça ou da infastabilidade da jurisdição. Questões relativas à existência, validade e eficácia da convenção de arbitragem e do contrato que possui a cláusula compromissória devem ser apreciadas pelo árbitro. Regra do 'kompetenz-kompetenz'. Princípio do Juízo Arbitral. Art. 8oㅡ caput e parágrafo único, da Lei 9307/96. Agravante que não teve tolhido qualquer direito acerca a nomeação do árbitro, na medida em que houve notificação da Câmara Arbitral garantindo-lhe tal faculdade. Participantes da arbitragem que possuem meios hábeis a demonstrar, de forma fundamentada sua discordância perante o juízo arbitral, consoante arts. 14, 15, 19 e 20 da Lei da Arbitragem, inclusive, se o caso, ulteriormente, por eventual afronta ao art. 21, par. 2, nos termos do art. 32 do mesmo diploma legal. Restando à parte a possibilidade de discutir perante árbitro ou câmara arbitral, de forma ampla, assuntos, teses e argumentos passíveis de irregularidades, mostrase prematuro o ajuizamento de demanda perante o Poder Judiciário. Arguição de extinção do processo sem resolução do mérito em contraminuta. Art. 267, inc. VII. Processos, cautelar e principal, extintos sem resolução do mérito. (TJ/SP, Agravo de Instrumento no 0037936-45.202.8.26.0000, j. 19.6.2012)

A opção das partes pela arbitragem pode ser estipulada pela inclusão em contratos ou estatutos de uma cláusula compromissória5 ("cheia" ou "em branco") antes do aparecimento da controvérsia ou do litígio; ou, ainda, depois deste, pelo compromisso arbitral ${ }^{6}$.

A cláusula cheia pode ser de duas espécies: $A d$ hoc ou avulsa - é aquela em que as partes fixam as regras e formas em que o processo arbitral será conduzido naquele caso específico -, ou Institucional - realizase por intermédio de uma entidade especializada que possui um regulamento próprio e uma relação de árbitros que as partes poderão indicar se não houver consenso entre um ou mais nomes.

De acordo com a jurisprudência a cláusula compromissória "cheia", ou seja, aquela em que as partes elegem, no mínimo, o órgão em que deverá ser proposta o compromisso arbitral é a mais adequada; pois na cláusula compromissória "em branco" pode surgir conflito entre as partes no momento da eleição do órgão, situação em que poderá ser necessária a interposição de ação judicial visando a sua definição. Nesse sentido:

[...] 2. A cláusula compromissória 'cheia', ou seja, aquela que contém, como elemento mínimo a eleição do órgão convencional de solução de conflitos, tem o condão de afastar a competência estatal para apreciar a questão relativa à validade da cláusula arbitral na fase inicial do procedimento (parágrafo único do art. $8^{\circ}$, c/c o art. 20 da LArb). 3. De fato, é certa a coexistência das competências dos juízos arbitral e togado relativamente às questões inerentes à existência, validade, extensão e eficácia da convenção de arbitragem. Em verdade excluindo-se a hipótese de cláusula compromissória 
patológica ('em branco') -, o que se nota é uma alternância de competência entre os referidos órgãos, porquanto a ostentam em momentos procedimentais distintos, ou seja, a possibilidade de atuação do Poder Judiciário é possível tão somente após a prolação da sentença arbitral, nos termos dos arts. 32, I e 33 da Lei de Arbitragem. 4. No caso dos autos, desponta inconteste a eleição da Câmara de Arbitragem Empresarial Brasil (CAMARB) como tribunal arbitral para dirimir as questões oriundas do acordo celebrado, o que aponta forçosamente para a competência exclusiva desse órgão relativamente à análise da validade da cláusula arbitral, impondo-se ao Poder Judiciário a extinção do processo sem resolução de mérito, consoante implementado de forma escorreita pelo magistrado de piso. Precedentes da Terceira Turma do STJ. 5. Recurso especial provido. (REsp 1278852/MG; DJe 19/06/2013)

Assim, feita a opção pela arbitragem para dar solução a litígio ou controvérsia, as partes firmam uma convenção de arbitragem ${ }^{7}$ em que, uma ou mais pessoas denominadas árbitros ${ }^{8}$ ou juízes arbitrais, de confiança das partes, irão, a partir do exercício neutro ou imparcial ${ }^{9}$ do conflito de interesses ${ }^{10}$, proferir uma decisão final, em caráter definitivo, uma vez que não cabe recurso ${ }^{11}$. As partes devem optar pela forma a ser adotada e condução do julgamento: equidade ou direito. $\mathrm{Na}$ arbitragem de direito o árbitro utiliza a lei para julgar; na equidade o árbitro julga utilizando o bom senso. A sentença arbitral ou decisão arbitral deve ser proferida no prazo de 6 (seis) meses, salvo estipulação em sentido contrário no momento do compromisso arbitral ${ }^{12}$.

Deste modo, a intervenção da justiça estatal somente se pode dar para garantir eficácia ou preservar direitos até a instalação da justiça arbitral, ou para ao final decidir sobre alegações de ilegalidades, mas de forma alguma para decidir as divergências entre as partes que por escrito estipularam a convenção de arbitragem ${ }^{13}$.

Não obstante, as Partes podem solicitar ao árbitro ou ao tribunal arbitral, no prazo de 5 (cinco) dias a contar do recebimento da notificação ou da ciência pessoal da sentença arbitral - espécie de embargos de declaração - que: (a) corrija qualquer erro material da sentença arbitral; ou (b) esclareça alguma obscuridade, dúvida ou contradição da sentença arbitral, ou se pronuncie sobre ponto omitido a respeito do qual devia manifestar-se a decisão.

O árbitro ou o tribunal arbitral decidirá, no prazo de dez dias, aditando a sentença arbitral e notificando as partes.
Os conceitos acima considerados revelam dois componentes fundamentais da estrutura da arbitragem: autonomia da vontade e o poder de julgar que os árbitros ${ }^{14}$ recebem em detrimento ao julgamento estatal.

A Lei 9.307/96 evidencia o caráter privado, mas também ressalta sua ótica jurisdicional ao dispensar a chancela do Poder Judiciário para ratificar a sentença arbitral.

Ressalta-se que o árbitro não tem poderes para compelir as partes ao cumprimento da sentença arbitral. Desse modo, a sentença poderá ser executada de duas maneiras: espontânea ou forçada. Neste caso a parte deverá recorrer à justiça para que se proceda a execução judicial (art. 475-P, CPC).

\section{A ARBITRAGEM NAS SOCIEDADES LIMITADAS}

O Código Civil de 2002 (CC/02) trata das sociedades limitadas nos artigos 1052 a 1087 . Naquilo que o CC/02 for omisso aplicam-se subsidiariamente, as disposições das sociedades simples. Isto poderá ser evitado com estipulação expressa no contrato social de que a legislação supletiva a ser aplicada será a da Lei 6.404/76. Assim, somente o contrato social poderá impedir que se apliquem supletivamente as regras das sociedades simples.

As deliberações dos sócios poderão ser tomadas em assembleia, fixando a lei determinados "quóruns" de deliberação para a aprovação de determinadas matérias ${ }^{15}$.

A arbitragem pode ser instituída na sociedade limitada em seu contrato social visando dirimir conflitos entre sócios, na liquidação da sociedade, entre sócios e sociedade e, ainda, na partilha de seu acervo ${ }^{16}$.

\subsection{0 alcance subjetivo da cláusula compromissória inserida no contrato social}

Há um requisito necessariamente de forma para a validade e eficácia da cláusula compromissória estatutária, que depende de sua específica e formal adoção por parte de todos os sócios. Sem essa expressa aprovação a cláusula compromissória é nula, por ferir o direito essencial do acionista de socorrer-se ao Poder Judiciário ${ }^{17}$.

Desta forma, a inserção no contrato social de uma cláusula compromissória requer a deliberação unânime dos sócios, afastando, assim, do Judiciário o conhecimento das causas nela descritas ${ }^{18}$. Caso a inserção da cláusula no contrato social tenha sido fruto de decisão da maioria do capital social, não vinculará os sócios que não tenham concordado com a adoção 
da arbitragem, por se tratar a arbitragem de instituto derivado de declaração personalíssima de vontade.

Destarte, decidindo a unanimidade dos sócios incluírem a cláusula de compromisso arbitral no contrato social, a supressão da referida cláusula, também requer a observância do mesmo quórum, sob pena do ajuste não obrigar os que não assentiram com a modificação.

Pedro A. Bastista Martins, ao tratar do tema, leciona que

[...] a estipulação da cláusula compromissória em alteração do contrato social de limitada, por votação majoritária, para se fixar a via arbitral para a solução de disputas sócio-sócio, poderá, em princípio, não vincular aqueles sócios que não assentiram com a modificação, porque, nesse particular, a relação jurídica pode reduzir-se a uma essência estritamente pessoal onde a repercussão patrimonial afete única e exclusivamente os bens, direitos e obrigações individuais do quotista sem qualquer reflexo na organização social. ${ }^{19}$

Nesse sentido:

DISSOLUÇÃO DE SOCIEDADE. CLÁUSULA DE COMPROMISSO ARBITRAL inserida em contrato social que deve prevalecer. Autonomia da clausula arbitral (art. 8oㅡ Lei 9630/96) em relação ao contrato. Princípio da competência-competência. Alteração contratual realizada unilateralmente pelo sócio majoritário para revogar tal cláusula que não pode ser tida como válida. Inadmissibilidade de ser processada a providência na justiça estatal, por constituir usurpação da competência. Preliminar que deve ser acolhida devendo ser extinto o processo sem resolução do mérito. Recurso não provido. (Apelação n⿳0 0007124-69.2012.8.26.0210, TJ/SP, 29.05.2014 $)^{20}$

Alguns autores, no entanto, admitem a possibilidade da aplicação da cláusula compromissória a quotistas que expressamente não tenham com ela concordado de forma expressa ou tácita. Dentre eles cita-se José Xavier Carvalho de Mendonça ${ }^{21}$ que defende o critério da maioria, in verbis:

Exigir a unanimidade seria expor a sociedade à inação, seria cair no absurdo de atribuir a um só acionista a qualidade de representante ou árbitro da vontade social. Adotando-se o critério da maioria, [...] não se sacrificam direitos nem interesses individuais dos sócios. Acha-se em causa o interesse exclusivo da pessoa jurídica da sociedade, abstraindo de considerações de ordem individual. A assembleia não representa a totalização das vontades individuais dos acionistas; é o órgão mais autorizado da vontade social. Os acionistas cooperam aí não como contratantes, porém com a vontade individual para produzirem uma só vontade, a da sociedade.

O princípio majoritário utilizado pelo direito societário preconiza que as decisões daqueles que detêm a maioria das quotas representativas do capital social, devem prevalecer em favor do interesse social da sociedade. E, é neste princípio, que se funda a defesa da doutrina que entende válida e obrigatória a cláusula compromissória para todos os sócios quando a mesma é aprovada pela maioria do capital social, porquanto se terá respeitado o princípio majoritário que a todos vincula ${ }^{22}$.

Por fim, esta corrente doutrinária argumenta que o sócio que não tenha participado da deliberação de sócios que tenha decidido pela inclusão da cláusula compromissória societária, ou, ainda, aquele que tenha expressamente dissentido de tal deliberação, não poderia, em momento posterior, obstar à realização de procedimento arbitral. A sua permanência na sociedade, na qualidade de sócio, importa em concordância expressa com o referido sistema de solução de controvérsias, haja vista este gozar de prerrogativa de se desligar, a qualquer tempo, da sociedade de que é sócio ${ }^{23}$.

\subsection{Dos limites da convenção de arbitragem}

A celebração de cláusula compromissória societária, sem que haja a restrição quanto às matérias submetidas à arbitragem ou a delimitação de reservas ao juízo estatal, estabelece a obrigatoriedade da utilização da arbitragem quanto a todos os conflitos que tenham incidência sobre o contrato social, desde que presentes os requisitos de arbitrabilidade subjetiva e objetiva.

Partindo-se do pressuposto de que a premissa supra é verdadeira, há que se admitir que a extensão da cláusula compromissória deva abranger toda e qualquer questão que se refira ao encontro de vontade dos sócios que deu origem à sociedade e que mantém o propósito social.

Nesse sentido:

Arbitragem. Lei no 9307/96. Convenção expressamente consignada na cláusula $13^{2}$ do contrato que estabelece a justiça arbitral para a solução de divergências entre os sócios. Clareza da cláusula e fragilidade do argumento de que só se aplicaria na divergência simples em deliberações sociais. Não há divergência maior entre os sócios do que aquela que enseja a pretensão de uns excluírem outro em dissolução parcial da sociedade limitada. Extinção do processo bem determinada pela $r$. sentença. 
Medida cautelar para preservar a administração da sociedade que deve ser mantida até a reapreciação pela justiça arbitral. Recurso improvido, com ordem de remessa da medida cautelar à Câmara de Arbitragem já constituída. (Apelação no: 001495943.2012.8.26.0361; TJSP; Julgado em 21.05.2013)

Na cláusula $13^{\underline{a}}$ do contrato social e alterações da Sociedade objeto da decisão supra transcrita constava, que: "No caso de divergência entre os sócios, a solução da mesma será confiada a um juizo arbitral composto de 03 (três) membros, sendo dois da escolha das partes divergentes, e o $3^{\circ}$ (terceiro) da nomeação dos 02 (dois) árbitros, com a função de desempatador". Claro, assim, que os sócios, ao firmarem o contrato social, afastandose da intervenção do Poder Judiciário, resolveram instituir a arbitragem como forma de solucionar todos os conflitos envolvendo as divergências societárias.

Assim, o juiz, tomando conhecimento da existência de demanda que visa à instauração do juízo arbitral, tem por dever apurar os limites objetivos e subjetivos da cláusula compromissória e manifestar-se a respeito do poder jurisdicional do Poder Judiciário para tal demanda.

Nesta análise pelos magistrados o que tem prevalecido, no entanto, é a interpretação restritiva do campo de incidência da convenção arbitragem, conforme se observa das decisões abaixo transcritas:

ADMINISTRAÇÃO DE SOCIEDADE. EXECUÇÃO DE CLÁUSULA ARBITRAL. INDEFERIMENTO DA INICIAL. Matéria relativa à dissolução da sociedade com apuração de haveres que não consta expressamente da clausula compromissória inserida no contrato social - Extinção do processo mantida - falta de interesse processual - Adoção dos fundamentos da sentença, em ração do permissivo do artigo 252 do Regimento Interno desta Egrégia Corte - Sentença mantida - Recurso Desprovido. Sublinhei. (Apelação no 0035142 61.2006.8.26.0000, Julgado em 18.01.2012).

Arbitragem. Cláusula compromissória prevista no contrato de constituição de sociedade comercial. Ação visando apurar responsabilidade dos administradores. Alegação de obrigatoriedade da arbitragem. Decisão afastando a alegação. Litígio que não envolve o contrato onde foi inserida a cláusula, mas os atos de administração da sociedade, não alcançados pela cláusula compromissória. Recurso desprovido. Sublinhei (AgIn 244.960-4/ 5-00; TJ/SP, Julgado em 11.09.202)

AÇÃO DECLARATÓRIA DE DISSOLUÇÃO DE SOCIEDADE CUMULADA COM
APURAÇÃO DE HAVERES. Decreto extintivo pela existência de cláusula compromissória de Juízo Arbitral, com verba honorária estipulada em $\mathrm{R} \$ 2.500,00$ para cada um dos advogados dos réus. Data da distribuição da ação: 28/07/2011. Valor da causa: $\mathrm{R} \$ 214.011,59$. Apela o autor sustentando já terem sido ajuizadas três demandas da mesma relação jurídica, sem os adversos suscitarem a incidência da cláusula; argüição apenas nesta sede configura ofensa ao princípio da boa-fé objetiva; cláusula compromissória vazia; sociedade já dissolvida; não sendo mais sócio não está submetido ao contrato social; direito de retirar-se da sociedade não se sujeita à arbitragem e não possui condições econômicas para pagamento de árbitros especializados; subsidiariamente, pela redução dos honorários advocatícios. Apelam os réus pugnando pela majoração da verba honorária. Cabimento do recurso do autor e prejudicados os reclamos dos réus. Cláusula compromissória diz respeito apenas a divergências entre os sócios. Autor já se retirou da sociedade. Questão remanescente de apuração de haveres e consequente constituição de crédito a ser satisfeito pela sociedade supera os limites estabelecidos para o Juízo arbitral. Pessoa jurídica não poderia participar da arbitragem, exceto se houvesse cláusula específica ou superveniente avenca que sujeitasse todos os envolvidos. Patrimônio dos sócios distinto daquele pertencente à sociedade. Decisão proferida no Juízo arbitral não seria capaz de impor à empresa uma obrigação de pagar. Recurso do autor provido para cassar a sentença e determinar o retorno dos autos à primeira instância para prosseguimento do feito em seus ulteriores termos. Prejudicados os recursos dos réus ${ }^{24}$. (Apelação no 0040815-93.2011.8.26.0506, TJ/SP, Julgado em 24.06.2014)

A partir da análise dos acórdãos das decisões acima transcritas verifica-se em todas as situações que as partes não cuidaram de especificar limites confiáveis para a submissão de controvérsias aos árbitros. Desta forma, a cláusula compromissória redigida de modo vago e impreciso, deu margem às mais diversas interpretações. E, assim, convém de fato dar à convenção arbitral interpretação restritiva ${ }^{25}$.

Outrossim, nada impede que as partes estabeleçam limites amplos na cláusula compromissória, desde que demarcáveis. Por outro lado, não se pode admitir que a cláusula seja aberta e ampla, de modo a envolver relações jurídicas que os contratantes não imaginaram $^{26}$.

Destarte, proposta ação judicial, contestando o réu não ser o juízo competente para apreciar a demanda em decorrência da cláusula compromissória prevista no contrato social, o magistrado deve pronunciar-se acerca 
da sua aplicabilidade à lide que lhe foi submetida. Se entender que lhe falece competência deve extinguir o processo judicial. Nesse mesmo sentido deve agir o árbitro, ou seja, este deve pronunciar-se a respeito não apenas da validade do contrato em que foi inserida a cláusula compromissória dada a independência da convenção arbitral, mas também a respeito da sua própria investidura como terceiro imparcial com poder jurisdicional de decidir a demanda ${ }^{27}$.

\subsection{Vantagens da utilização da arbitragem}

A especialização das demandas societárias obriga, cada vez mais, a presença de profissionais qualificados para encontrar a solução ideal, nem sempre presente no juízo estatal. Destarte inegável que o instituto da arbitragem proporciona inúmeras vantagens, dentre elas cita-se ${ }^{28}$ :

a) evita as prolongadas contendas entre os sócios ou entre estes e a própria sociedade;

b) o conflito é resolvido de maneira sigilosa, preservando a confidencialidade de possíveis informações estratégicas da sociedade;

c) evita qualquer tipo de exposição que possa atingir a reputação da sociedade no meio empresarial no qual a mesma atua;

d) evita qualquer tipo de constrangimento para as sociedades que procuram contratar com o Governo e se encontram impedidas por figurarem como parte em disputas no Judiciário;

e) a demanda é analisada por especialistas plenamente conhecedoras na matéria do litígio.

\section{CONCLUSÃO}

A Lei 9307/96 deu às partes a liberdade de escolha para que pudessem resolver os seus litígios através de árbitros particulares, de tal modo que não precisassem recorrer ao Estado. Essa liberdade de escolha não pode ser contestada, porque está limitada a direitos disponíveis e quanto a esses direitos a parte pode renunciar ao direito de ação.

Por outro lado, ainda não existe consenso de que seja válida para todos os sócios da sociedade limitada cuja inclusão se deu em razão da decisão da maioria no melhor interesse da Sociedade, apesar do direito das sociedades limitadas permitir, regra geral, mudanças no contrato social por decisão majoritária, sem que desse ato resulte quebra contratual ou direito a perdas e danos.

A redação da cláusula compromissória deve ser precisa e clara, para evitar interpretações não desejadas pelos contratantes.
Não obstante, não restam dúvidas que a adoção da arbitragem para dirimir conflitos oriundos da relação societária contribui para a melhor realização do objeto social da sociedade.

A adoção da arbitragem no Brasil em larga escala, no entanto, depende de uma verdadeira revolução cultural, de tal modo que todos acreditem na seriedade desse procedimento como solução de litígios.

\section{REFERÊNCIAS}

CANTIDIANO, Luiz Leonardo. Reforma da Lei das S/A comentada. Rio de Janeiro: Renovar, 2002.

CARMONA, Carlos. Jurisprudência Comentada. Contrato de Constituição de Sociedade Comercial. Responsabilidade de administrador. Obrigatoriedade da arbitragem. Efeito negativo da cláusula compromissória. In: Revista de Arbitragem e Mediação, RT, ano 1, n. 2, p. 287-293, maio-ago. 2004.

CARVALHOSA, Modesto; EIZIRK, Nelson. A nova Lei das S/A. São Paulo: Saraiva, 2002.

COELHO, Fábio Ulhoa. Curso de Direito Comercial - Direito de Empresa. São Paulo: Saraiva, 2014. Vol. 2.

FINKELSTEIN, Claudio. Arbitragem no Direito Societário. In: FINKELSTEIN. Maria Eugênia Reis; PROENÇA, José Marcelo Martins (Coord.). Sociedades Anônimas. São Paulo: Saraiva 2007. (Série GVlaw). p. 301-321.

KATZWINKEL, Edgard. A Arbitragem como procedimento eficaz para a solução dos conflitos (entre sócios e a sociedade) nas sociedades empresárias. Mediação, arbitragem e conciliação. (Coord. Eduardo de Oliveira Leite). Rio de Janeiro: Forense, 2008. p. 73-104.

MAKANT, Bárbara. A arbitrabilidade subjetiva nas Sociedades Anônimas. In: Revista de Arbitragem e Mediação, RT, ano 2, n. 4, p. 82-103, jan.-mar. de 2005.

MARTINS, Pedro A. Bastista. A Arbitragem nas Sociedades de Responsabilidade Limitada. In: Revista de Direito Mercantil, v. 126.

MENDONÇA, José Xavier Carvalho, apud PELA, Juliana Krueger. Notas sobre a eficácia da Cláusula Compromissória Estatutária. Revista de Direito Mercantil, Industrial, Econômico e Financeiro, v. 126, abr.-jun. 2002.

MIRANDA, Maria Bernadete; MALUF, Clóvis Antonio. Curso teórico e prático de Mediação, Conciliação e Arbitragem. Rio de Janeiro: GZ Ed., 2013.

REQUIÃO. Rubens. Curso de Direito Comercial. São Paulo: Saraiva, 2003. Vol. 2

SCAVONE JÚNIOR. Luiz Antonio. Manual de arbitragem, mediação e conciliação. Rio de Janeiro: Forense, 2014.

TOMAZETTE, Marlon. Curso de Direito Empresarial: Teoria geral e direito societário. São Paulo: Atlas, 2008. Vol. 2.

VILELA, Marcelo Dias Gonçalves. Jurisprudência Comentada. Sociedade por Cotas de Responsabilidade Limitada Composta por Apenas Dois Sócios. Exclusão do Sócio Minoritário Ditada pelo Sócio Majoritário Sob o Fundamento da Justa Causa. Previsão de Arbitragem. Execução Específica. Revista de Arbitragem e Mediação, RT (Coord. Arnoldo Wald), ano 2, n. 5, p. 172-183, abr.-jun. 2005

WALD Arnoldo. Novos rumos para a Arbitragem no Brasil. Revista de Direito Bancário, do Mercado de Capitais e da Arbitragem, n. 14, abr.-jun. 2002.

YARSHELL, Flávio Luiz; PEREIRA, Guilherme Setoguti J. (Coord.). Processo Societário. São Paulo: Quartier Latin, 2012. 


\section{NOTAS}

${ }^{1}$ MIRANDA, Maria Bernadete; MALUF, Clóvis Antonio. Curso teórico e prático de Mediação, Conciliação e Arbitragem. Rio de Janeiro: GZ Ed., 2013, p. 54-55.

2 SCAVONE JÚNIOR. Luiz Antonio. Manual de Arbitragem, Mediação e Conciliação. Rio de Janeiro: Forense, 2014, p. 16.

${ }^{3}$ MAKANT, Bárbar. A Arbitrabilidade Subjetiva nas Sociedades Anônimas. In: Revista de Arbitragem e Mediação, ano 2, n. 4, p. 83 , jan.-mar. 2005.

${ }^{4}$ Direitos patrimoniais são aqueles que podem ser considerados em sua expressão econômica.

${ }^{5}$ É a convenção onde as partes em um contrato comprometem-se a submeter à arbitragem os litígios eventualmente derivados do contrato.

${ }^{6}$ É o ato formal e por escrito que dá início ao processo de arbitragem. Artigo 9ํㅡ, Lei 9.307/96: O compromisso arbitral é a convenção através da qual as partes submetem um litígio à arbitragem de uma ou mais pessoas, podendo ser judicial ou extrajudicial.

7 Art. 3 - da Lei 9307/96. As partes interessadas podem submeter a solução de seus litígios ao juízo arbitral mediante convenção de arbitragem, assim entendida a cláusula compromissória e o compromisso arbitral.

8 Art. 13 da Lei 9307/96. Pode ser árbitro qualquer pessoa capaz e que tenha a confiança das partes.

9 Art. 14 da Lei 9307/96. Estão impedidos de funcionar como árbitros as pessoas que tenham, com as partes ou com o litigio que lhes for submetido, algumas das relações que caracterizam os casos de impedimento ou suspeição de juizes, aplicando-se-lhes, no que couber os mesmos deveres e responsabilidades, conforme previsto no Código de Processo Civil.

$\S 1^{\circ}$ As pessoas indicadas para funcionar como árbitro tem o dever de revelar, antes da aceitação da função, qualquer fato que denote dúvida justificada quanto à sua imparcialidade e independência. [...]

10 Art. 13 [...] \& 6으 da Lei 9307/96. No desempenho de sua função, o árbitro deverá proceder com imparcialidade, independência, competência, diligência e discrição.

${ }^{11}$ Art. 18 da Lei 9307/96. O árbitro é juiz de fato e de direito, e a sentença que proferir não fica sujeita a recurso ou a homologação pelo Poder Judiciário.

${ }^{12}$ Art. 31. da Lei 9307/96. A sentença arbitral produz, entre as partes e seus sucessores, os mesmos efeitos da sentença proferida pelos órgãos do Poder Judiciário e, sendo condenatória, constitui título executivo.

13 "Uma vez exercida a autonomia privada para lhes atribuir jurisdição, os árbitros terão competência exclusiva à resolução do mérito da controvérsia que se lhes foi posta. À justiça estatal restarão intervenções pontuais, aqui sumária e esquematicamente expostas, as quais se articulam ao aparato normativo destacado a concretizar sentenças arbitrais ou, no geral, a eficacizar ou ineficacizar, no todo ou em parte, a arbitragem. Tratam-se, portanto, do que se pode chamar genericamente de 'intervenções eficacizantes', não porque invariavelmente atribuem efeitos à convenção ou à sentença arbitrais, mas porque ao fazê-lo, ou mesmo quando lhes cassam tais efeitos, fazem-no para promover a concreção da autonomia privada exercida." (A arbitragem e os limites à atuação do Judiciário nos Litígios Societários. In: YARSHELL, Flávio Luiz; PEREIRA, Guilherme Setoguti J. (Coord.). Processo Societário. São Paulo: Quartier Latin, 2012, p. 728).

${ }^{14}$ Art. 17 da Lei 9307/96. Os árbitros, quando no exercício de suas funções ou em razão delas, ficam equiparados aos funcionários públicos, para os efeitos da legislação penal.

${ }^{15}$ KATZWINKEL, Edgard. A Arbitragem como procedimento eficaz para a solução dos conflitos (entre sócios e a sociedade) nas sociedades empresárias. Mediação, arbitragem e conciliação. (Coord. Eduardo de Oliveira Leite), Rio de Janeiro: Forense, 2008, p. 88.

${ }^{16}$ FINKELSTEIN, Claudio. Arbitragem no Direito Societário. In: FINKELSTEIN. Maria Eugênia Reis; PROENÇA, José Marcelo Martins (Coord.). Sociedades Anônimas. São Paulo: Saraiva, 2007, (Série GVlaw), p. 310.

${ }^{17}$ MAKANT, Bárbara. A arbitrabilidade subjetiva nas Sociedades Anônimas. In: Revista de Arbitragem e Mediação, ano 2, n. 4, p. 85 , jan.-mar. 2005.
${ }^{18}$ Nesse sentido CARVALHOSA, Modesto; EIZIRK, Nelson. A Nova Lei das S/A. São Paulo: Saraiva, 2002, p. 183. CANTIDIANO, Luiz Leonardo. Reforma da Lei das S/A comentada. Rio de Janeiro: Renovar, 2002.

${ }^{19}$ MARTINS, Pedro A. Bastista. A Arbitragem nas sociedades de responsabilidade limitada. In: Revista de Direito Mercantil, v. 126, p. 64.

${ }^{20}$ Mister transcrever parte do fundamento da decisão proferida na Apelação no 0007124-69.2012.8.26.0210, TJ/SP, 29.05.2014: “[...] Registre-se que o contrato poderia ser modificado, como foi (arts. 1071, V, do CC e 1076, I, do CC) porque o detentor de mais de três quartos votou pela modificação e fim da arbitragem. No entanto e como existe discussão sobre a legalidade dessa modificação, devido às impugnações feitas, essa questão também deve se submeter ao crivo dos árbitros e não do Poder Judiciário. Isso decorre da aplicação do princípio competênciacompetência prevista no art. 8 o da Lei de Arbitragem e somente estaria derrogada a competência convencionada caso as partes, por consenso, tivessem alterado [...]. Seguindo esse raciocínio que decorre da lógica do sistema e da interpendência dos regimes, não está o Judiciário autorizado a, nesse instante, reputar válida a exclusão da cláusula arbitral pela modificação unilateral do contrato, ainda que detenha a autora a maior parte das quotas sociais. Isso, porque, é sabido que a cláusula que institui o compromisso arbitral é autônoma em relação ao negócio jurídico a que ela está inserta. E por ter esta característica não segue as regras dos artigos 1071, V, do CC e 1076, I, do CC. Ou seja, é condição de eficácia da afirmada alteração o consenso de todos os interessados, de modo que não se faz presente o requisito autonomia privada, que consiste na manifestação de vontade livre e consciente do sujeito de direitos. [...]"

${ }^{21}$ MENDONÇA, José Xavier Carvalho. Apud. PELA, Juliana Krueger. Notas sobre a eficácia da Cláusula Compromissória Estatutária. Revista de Direito Mercantil, Industrial, Econômico e Financeiro, v. 126, abr.jun. 2002, p. 133.

22 MAKANT, Bárbara. A Arbitrabilidade Subjetiva nas Sociedades Anônimas. In: Revista de Arbitragem e Mediação, RT, ano 2, n. 4, jan.mar. 2005, p. 88-89.

${ }^{23}$ MAKANT, Bárbara. A arbitrabilidade subjetiva nas sociedades anônimas. In: Revista de Arbitragem e Mediação, ano 2, n. 4, p. 91, jan.-mar. 2005.

${ }^{24} \mathrm{O}$ contrato social da Sociedade objeto da decisão supra transcrita, no tópico acerca da arbitragem, dispunha, in verbis: "As divergências que se verificarem entre os sócios, inclusive no caso de falecimento de um deles entre os seus herdeiros e o remanescente, serão resolvidas mediante juizo arbitral, ficando eleito o foro da Comarca de Ribeirão Preto SP". Ocorre que a questão tratada no processo referente a decisão supra não se limitava a divergências entre os sócios. O escopo é de apuração de haveres e conseqüente recebimento do valor devido em ação de dissolução parcial (resolução da sociedade em relação a um dos sócios), possui natureza de ressarcimento a ser satisfeito pela sociedade. Nesse sentido: "Consoante jurisprudência desta Corte, a retirada de sócio de sociedade por quotas de responsabilidade limitada dá-se pela ação de dissolução parcial, com apuração de haveres, para qual têm de ser citados não só os demais sócios, mas também a sociedade" (Resp. 1371843/SP, julgado em 20.03.2014). Face ao que antecede a sociedade, devedora do valor a ser apurado, não poderia participar da arbitragem, exceto se houvesse cláusula específica ou superveniente avença que sujeitasse todos os envolvidos ao Juízo arbitral.

${ }^{25}$ CARMONA, Carlos. Jurisprudência comentada. Contrato de Constituição de Sociedade Comercial. Responsabilidade de administrador. Obrigatoriedade da arbitragem. Efeito negativo da cláusula compromissória. In: Revista de Arbitragem e Mediação, RT, ano 1, n. 2, p. 292, maio-ago. 2004.

${ }^{26}$ CARMONA, Carlos. Op. cit., p. 293.

27 VILELA, Marcelo Dias Gonçalves. Jurisprudência comentada. Sociedade por cotas de responsabilidade limitada composta por apenas dois sócios. Exclusão do sócio minoritário ditada pelo sócio majoritário sob o fundamento da justa causa. Previsão de arbitragem. Execução específica. Revista de Arbitragem e Mediação, RT, Coordenação Arnoldo Wald, ano 2, n. 5, abr.-jun. 2005.

${ }^{28}$ Conforme WALD Arnoldo. Novos rumos para a arbitragem no Brasil. Revista de Direito Bancário, do Mercado de Capitais e da Arbitragem, n. 14, p. 341, abr.-jun. 2002. 